\title{
Distinct Oscillatory Frequencies Underlie Excitability of Human Occipital and Parietal Cortex
}

\author{
어 Jason Samaha, ${ }^{1}$ Olivia Gosseries, ${ }^{2,3}$ and Bradley R. Postle ${ }^{1,2}$ \\ ${ }^{1}$ Department of Psychology and ${ }^{2}$ Department of Psychiatry, University of Wisconsin, Madison, Wisconsin 53704, and ${ }^{3}$ Coma Science Group, GIGA \\ consciousness research, University and University Hospital of Liège, 4000 Liège-Belgium
}

Transcranial magnetic stimulation (TMS) of human occipital and posterior parietal cortex can give rise to visual sensations called phosphenes. We used near-threshold TMS with concurrent EEG recordings to measure how oscillatory brain dynamics covary, on single trials, with the perception of phosphenes after occipital and parietal TMS. Prestimulus power and phase, predominantly in the alpha band $(8-13 \mathrm{~Hz})$, predicted occipital TMS phosphenes, whereas higher-frequency beta-band (13-20 Hz) power (but not phase) predicted parietal TMS phosphenes. TMS-evoked responses related to phosphene perception were similar across stimulation sites and were characterized by an early $(200 \mathrm{~ms})$ posterior negativity and a later $(>300 \mathrm{~ms})$ parietal positivity in the time domain and an increase in low-frequency $(\sim 5-7 \mathrm{~Hz})$ power followed by a broadband decrease in alpha/beta power in the time-frequency domain. These correlates of phosphene perception closely resemble known electrophysiological correlates of conscious perception of near-threshold visual stimuli. The regionally differential pattern of prestimulus predictors of phosphene perception suggests that distinct frequencies may reflect cortical excitability in occipital versus posterior parietal cortex, calling into question the broader assumption that the alpha rhythm may serve as a general index of cortical excitability.

Key words: cortical excitability; occipital; oscillations; parietal; phosphenes; visual perception

Significance Statement

Alpha-band oscillations are thought to reflect cortical excitability and are therefore ascribed an important role in gating information transmission across cortex. We probed cortical excitability directly in human occipital and parietal cortex and observed that, whereas alpha-band dynamics indeed reflect excitability of occipital areas, beta-band activity was most predictive of parietal cortex excitability. Differences in the state of cortical excitability predicted perceptual outcomes (phosphenes), which were manifest in both early and late patterns of evoked activity, revealing the time course of phosphene perception. Our findings prompt revision of the notion that alpha activity reflects excitability across all of cortex and suggest instead that excitability in different regions is reflected in distinct frequency bands.

\section{Introduction}

Transcranial magnetic stimulation (TMS) can elicit muscle contractions when applied over motor cortex (Merton et al., 1982) and can induce visual sensations (phosphenes) when applied over regions of occipital cortex (Kammer et al., 2005). These phenomena can be used to study variability in the state

\footnotetext{
Received Nov. 3, 2016; revised Jan. 26, 2017; accepted Jan. 31, 2017.

Author contributions: J.S. and B.R.P. designed research; I.S. and 0.G. performed research; I.S. analyzed data; I.S., O.G., and B.R.P. wrote the paper.

This work was supported by National Institutes of Health grant R01MH095984 (to B.R.P.) and the Belgian National Fund for Scientific Research (FNRS) and Human Brain Project grant EU-H2020-FETFLAGSHIP-HBP-SGA1GA720270 (to 0.G.).

The authors declare no competing financial interests.

Correspondence should be addressed to Jason Samaha, Department of Psychology, University of Wisconsin, 1202

W. Johnson St., Madison, WI 53703. E-mail: jsamaha@wisc.edu.

DOI:10.1523/JNEUROSCI.3413-16.2017

Copyright $\odot 2017$ the authors $\quad 0270-6474 / 17 / 372824-10 \$ 15.00 / 0$
}

of cortical excitability of the tissue undergoing stimulation by measuring changes in the magnitude or likelihood of these responses as stimulation parameters are kept constant (PascualLeone et al., 1998). When TMS is combined with concurrent EEG recordings, variability in cortical excitability can be linked to variability in ongoing neural activity. Using this approach, prior work has found that the power of oscillatory neural activity in the alpha band $(8-13 \mathrm{~Hz})$ before the onset of TMS is negatively correlated with both phosphene perception (Romei et al., 2008a) and the likelihood and magnitude of motor-evoked potentials (Zarkowski et al., 2006; Sauseng et al., 2009). These findings are taken as evidence that cortical excitability is regulated by neuronal oscillations in the alpha range (Jensen and Mazaheri, 2010). Recent studies have also found that the prestimulus alpha phase is predictive of the perception of phosphenes (Dugué et al., 2011) and visual stimuli (Busch et al., 2009; Mathewson et al., 2009; Samaha et al., 2015), leading to the proposal that alpha 
may impose inhibition in a phasic manner (Mathewson et al., 2011).

Because this approach relies on stimulating brain areas that give rise to observable or reportable responses, previous work has been limited to investigating the excitability of visual and motor cortices. Recently, however, several groups have reported that TMS of posterior parietal cortex (PPC) can also give rise to phosphenes (Marzi et al., 2009; Mazzi et al., 2014; Tapia et al., 2014; Bagattini et al., 2015). Although the phenomenology of PPC phosphenes has been reported to be comparable to those elicited from occipital stimulation (Fried et al., 2011), the physiological correlates of the two have not been compared directly. We therefore undertook characterization of the cortical excitability of PPC and compared it with occipital cortex by applying TMS at phosphene-threshold levels to both areas while recording EEG. If alpha-band dynamics reflect cortical excitability in PPC, then alpha power and/or phase would also be predictive of parietal TMS phosphenes. Alternatively, oscillations in the lower beta-band $(13-30 \mathrm{~Hz})$ may play this role for PPC because beta has been proposed as the "natural frequency" of PPC on the basis of the observation that the dominant EEG response to PPC TMS is $\sim 20 \mathrm{~Hz}$ (Rosanova et al., 2009; Ferrarelli et al., 2012). Furthermore, prestimulus dynamics of $\sim 20 \mathrm{~Hz}$ predict the global mean field amplitude of the EEG response to TMS of PPC (Kundu et al., 2014).

Our approach also allowed us to investigate the neural correlates of TMS-evoked phosphene perception. Prior work using visual stimuli has focused on two ERP components that vary with awareness: an early posterior "visual-awareness negativity" (VAN) and a late central-parietal positivity (LP) (for review, see Koivisto and Revonsuo, 2010; Railo et al., 2011). Our study allowed us to investigate whether these components generalize to the perception of phosphenes. Because spontaneous and TMSevoked brain activity fluctuates from trial-to-trial in a continuous manner, we hypothesized that the perceptual states linked to these fluctuations would also vary continuously. We tested this hypothesis by measuring the strength of phosphene perception on a continuous scale ranging from "clearly present" to "clearly absent." These reports served as responses for single-trial regression analyses relating phosphene perception to fluctuations in EEG voltage, power, and phase. Our findings reveal the temporal and oscillatory dynamics of neural activity related monotonically to phosphene perception induced by occipital and parietal TMS and suggest that, whereas alpha-band oscillations reflect cortical excitability of occipital cortex, beta power reflects excitability of parietal cortex.

\section{Materials and Methods}

Subjects. Seventeen subjects were recruited for the experiment for monetary compensation. After phosphene screening, which entailed singlepulse stimulation of right occipital and right parietal cortex at up to $90 \%$ of maximum stimulator output, 10 subjects ( 8 male; $24-33$ years old) who perceived phosphenes reliably at both stimulation sites were retained for EEG recording. This proportion is consistent with reports of $60-80 \%$ of subjects who perceive occipital TMS phosphenes without extensive training and resulted in a sample size comparable to previous TMS-EEG experiments examining phosphenes (Romei et al., 2008a; Dugué et al., 2011; Bagattini et al., 2015). All subjects were recruited from the University of Wisconsin-Madison community. The University of Wisconsin-Madison Health Sciences Institutional Review Board approved the study protocol. All subjects gave informed consent and were screened for the presence of neurological and psychiatric conditions and other risk factors related to the application of TMS.

Stimulation and phosphene thresholding. As described previously (Marzi et al., 2009; Fried et al., 2011), stimulation of right occipital cortex was delivered over electrode $\mathrm{O} 2$ and stimulation of right PPC was delivered over electrode $\mathrm{P} 4$. The coil handle was oriented medial to lateral, away from the inion, during occipital stimulation and ventromedial to dorsolateral, pointing away from the inion for parietal stimulation (see arrows in Fig. $1 B$ ). The final coordinates of stimulation were then determined functionally by slightly adjusting the coil until phosphenes were elicited reliably. Phosphene perception was considered reliable if participants reported them in the visual field contralateral to stimulation and if they ceased with decreased stimulation intensity. To ensure consistent stimulation throughout the experiment, the final stimulation coordinates were saved and visualized using a navigated brain stimulation (NBS) system (Nexstim) that uses infrared-based frameless stereotaxy to map the position of the coil and the subject's head within the reference space of the individual's high-resolution T1-weighted anatomical MRI (acquired with a GE MR750 $3 \mathrm{~T}$ scanner for each subject before the experiment). During EEG recording, the coil was held in place by the experimenter, who monitored the NBS system to maintain consistent stimulation coordinates. Phosphene thresholds were defined for each subject and stimulation site before the experiment as the stimulator intensity that lead to a $50 \%$ rate of phosphene reports (yes/no verbal response) after 10 single-pulse stimulations. This was accomplished by increasing stimulator intensity until a phosphene was reported and then adjusting stimulator intensity in $1 \%$ steps until $5 / 10$ phosphenes were reported. As noted in prior work (Fried et al., 2011; Tapia et al., 2014; Bagattini et al., 2015), parietal TMS phosphene thresholds required higher stimulator intensities $(M=83.2 \%$ of maximum stimulator output, $\mathrm{SD}=9.2)$ than occipital $(M=71.9 \%, \mathrm{SD}=8.1)$. A thin layer of foam was placed between the coil and the EEG cap to help minimize TMS artifacts and auditory artifacts due to bone conduction (Massimini et al., 2005). This resulted in a higher intensity stimulator output (compared with prior work), to achieve phosphene thresholds. TMS was delivered with a Magstim Super Rapid ${ }^{2}$ magnetic stimulator fit with a focal bipulse, figure of eight $70 \mathrm{~mm}$ stimulating coil.

Experimental session. Each subject completed eight blocks of 100 trials each. Single-pulse TMS was delivered to occipital cortex on half of the blocks and to parietal cortex on the remaining half. Occipital and parietal stimulation blocks were interleaved and the order was counterbalanced across participants. The task is depicted in Figure 1A. Each trial began with a random intertrial interval between 1000 and $1500 \mathrm{~ms}$ during which a dark gray fixation cross was presented atop a black background. After each pulse of TMS, subjects' maintained central fixation for $1 \mathrm{~s}$, at which point a dark grayscale appeared. The left and right end points of the semicontinuous scale were respectively labeled "clearly absent" and "clearly present." (Although no digits appeared along the response display, responses were recorded by the computer as an integer value ranging from " 0 " at the extreme left of the bar to " 100 " at the extreme right.) Subjects were instructed to rate the presence of phosphenes by sliding a computer mouse with their right hand to the appropriate position on the scale and clicking the mouse. A perpendicular bar marked the current scale position that was reset to the center of the scale on each trial, which subjects were informed corresponded to an "unsure" response. Therefore, this scale captured the subjective certainty or clarity of phosphenes in a monotonic fashion, with increasing values indicating greater subjective certainty in the presence of phosphenes. As a check of basic task compliance, TMS was not delivered on $5 \%$ of all trials (randomly determined), which, if subjects understood the scale, we expect would result in reports near zero.

EEG acquisition and preprocessing. EEG was recorded from $60 \mathrm{Ag} / \mathrm{AgCl}$ electrodes connected to a TMS-compatible amplifier (Nexstim). This amplifier avoids saturation from the TMS pulse with a sample-and-hold circuit that holds amplifier output constant from $100 \mu$ s before to $2 \mathrm{~ms}$ after stimulus. Impedance at each electrode was kept at $<5 \mathrm{k} \Omega$. A single electrode placed on the forehead was used as the reference and eye movements were recorded with two additional electrodes placed below and on the outer side of the right eye. Data were acquired at a rate of $1450 \mathrm{~Hz}$ with 16-bit resolution. To reduce contamination of the EEG by auditory responses from TMS, masking white noise was played through inserted earplugs throughout the experimental session, as in previous experiments in our laboratory (Kundu et al., 2014). EEG was processed offline 
with custom MATLAB scripts (version R2014b) and with the EEGLAB toolbox version 13.5 (Delorme and Makeig, 2004). Recordings were inspected visually and noisy channels (3.9 on average) were spherically interpolated. Data were downsampled to $500 \mathrm{~Hz}$ and re-referenced to the average of all electrodes. Because, for some subjects, residual high-amplitude artifacts persisted for 20-30 $\mathrm{ms}$ after TMS, the data from -10 to $40 \mathrm{~ms}$ surrounding each TMS pulse was removed and interpolated via robust splines (Garcia, 2010). These artifacts resembled those caused by stimulation of cranial muscles and occurred in some subjects due to the choice of stimulation site being optimized for eliciting phosphenes, making the window from -10 to $40 \mathrm{~ms}$ difficult to interpret. A one-pass zero-phase Hamming windowed-sinc FIR filter between 0.5 and $50 \mathrm{~Hz}$ was applied to the data (EEGLAB function "pop_eegfiltnew.m") and epochs spanning -1500 to 1500 relative to TMS onset were extracted. A prestimulus baseline of -200 to -10 was then subtracted from each trial. Individual trials were then inspected visually and those containing muscle artifacts or ocular artifacts occurring contemporaneously with TMS onset were removed, resulting in an average of 322 occipital stimulation and 323 parietal stimulation trials remaining per subject. Independent components analysis using the INFOMAX algorithm (EEGLAB function "binica.m") was used to remove remaining ocular artifacts not coinciding with TMS, as well as artifactual components clearly related to TMS. An average of 2.7 ocular artifacts and 6.8 TMS-related artifacts were removed per subject. Raw data and commented code used for all preprocessing and analysis are freely available for download through the Open Science Framework (https://osf.io/6qu3b/).

Time-domain analysis. To relate continuously varying perceptual ratings to continuously varying voltage across time, we performed nonparametric robust regression on single-trial data. For each time point, electrode, and subject, regression coefficients that describe the monotonic relationship between voltage and phosphene presence ratings were estimated according to the following linear model:

$$
\beta=X^{\mathrm{T}} X^{-1} X^{\mathrm{T}} D
$$

where $X$ is the design matrix containing one column for the intercept (all ones) and one column for perceptual ratings across trials; the superscripts " $\mathrm{T}$ " and " -1 " indicate the matrix transpose and inverse, respectively; and $D$ is the vector of voltage data from all trials at a given time point. The resulting beta coefficient representing the slope of the voltagephosphene relationship was then converted into a $z$-statistic relative to a subject-specific null hypothesis distribution obtained by repeatedly shuffling the mapping between ratings and voltage (see "Statistics" section). Before regression, the voltage data were smoothed with a $20 \mathrm{~ms}$ sliding average window and both phosphene ratings and voltage were rank scored to mitigate the influence of outlying data while testing for a monotonic relationship (this is equivalent to computing a Spearman's correlation coefficient). These normalized beta coefficients were then averaged over a cluster of posterior electrodes (visualized in Fig. $2 B$, inset) to improve the signal-to-noise ratio. To validate this procedure against a more traditional time-domain analysis approach, trialaveraged ERPs were also computed by sorting trials into "phosphene present" and "phosphene absent" bins if they were greater than (less than) the $55^{\text {th }}\left(45^{\text {th }}\right)$ percentile of the scale (to exclude middle "unsure" trials). As described previously (Pitts et al., 2014b; Railo et al., 2015; Shafto and Pitts, 2015), the LP/P3 potential was examined at the central

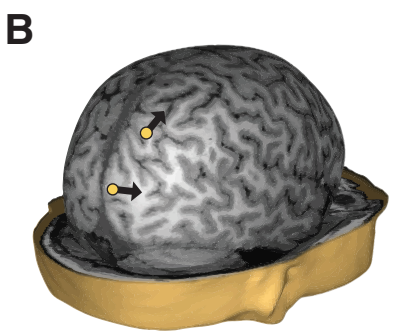

Parietal TMS
Occipital TMS
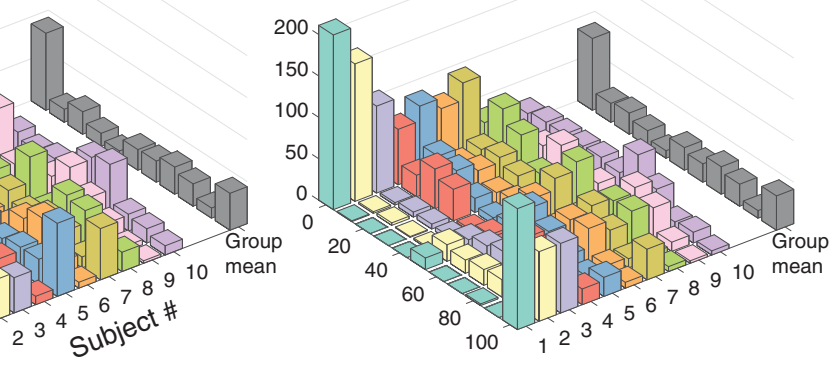

Figure 1. Task design, stimulation sites, and phosphene report distributions. $A$, After a variable intertrial interval of $1-1.5 \mathrm{~s}$, a single pulse of TMS was delivered at individual phosphene thresholds. One second after TMS, subjects reported the presence of the from a representative subject and the arrows indicate the orientation of the handle of the TMS coil. C, Distributions of phosphene reports for individual subjects and for the group level after occipital and parietal TMS.

parietal electrode $\mathrm{Pz}$ and the VAN was examined at occipital electrode Oz. Time windows for each component were determined from data orthogonal to later statistical contrasts by inspecting the conditionaveraged ERP. VAN was averaged over a window that spanned 180-220 $\mathrm{ms}$ and the LP over a window that spanned 300-800 ms.

Time-frequency analysis. The same single-trial regression approach was used to relate time-frequency power to phosphene perception. Time-frequency decomposition was performed by convolving data from each trial with a family of complex Morlet wavelets spanning $2-50 \mathrm{~Hz}$ in $1.23 \mathrm{~Hz}$ steps, with wavelet cycles increasing linearly between 3 and 8 cycles as a function of frequency. Power was obtained by squaring the absolute value of the resulting complex time series and was converted to percentage signal change relative to a prestimulus baseline of -600 to $-100 \mathrm{~ms}$ to adjust for power law scaling. After regression, normalized beta coefficients were then averaged over the same cluster of posterior electrodes that was used in the time-domain regression analysis (see above). Due to the temporal smearing inherent in time-frequency decomposition, caution must be used when analyzing prestimulus effects, particularly with respect to phase (Zoefel and Heil, 2013), which can result from a confound due to contamination of prestimulus data by poststimulus differences. Therefore, we focused further on prestimulus power and phase by performing an FFT on data segments cut from -1000 to $-50 \mathrm{~ms}$ before TMS onset. Before the FFT, these segments were linearly detrended, multiplied by a Hamming window, and zero padded (frequency resolution: $0.1 \mathrm{~Hz}$ ). Power was extracted by squaring the absolute value of the Fourier coefficients and phase was obtained by taking the angle (MATLAB function "angle.m"). Single-trial prestimulus power was related to phosphene perception as before and was also binned into high and low ratings, again, to illustrate differences in a more traditional manner. For this analysis, power was $\log _{10}$ transformed and averaged over the alpha band $(8-13 \mathrm{~Hz})$ and low-beta band $(13-20 \mathrm{~Hz})$.

Because phase is a circular variable, it cannot be related to a linear variable by means of ordinary linear regression. We therefore computed a recently introduced measure of circular-linear association called "weighted intertrial phase clustering" (wITPC) (Cohen and Cavanagh, 


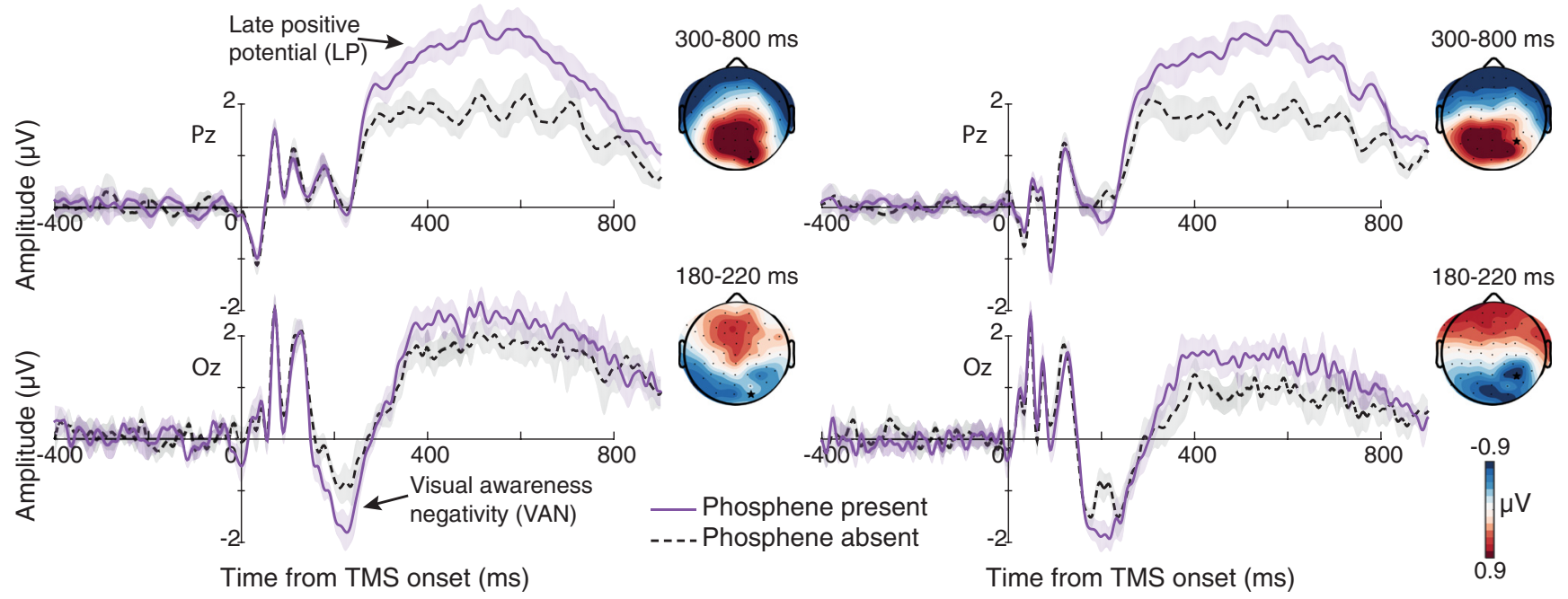

B
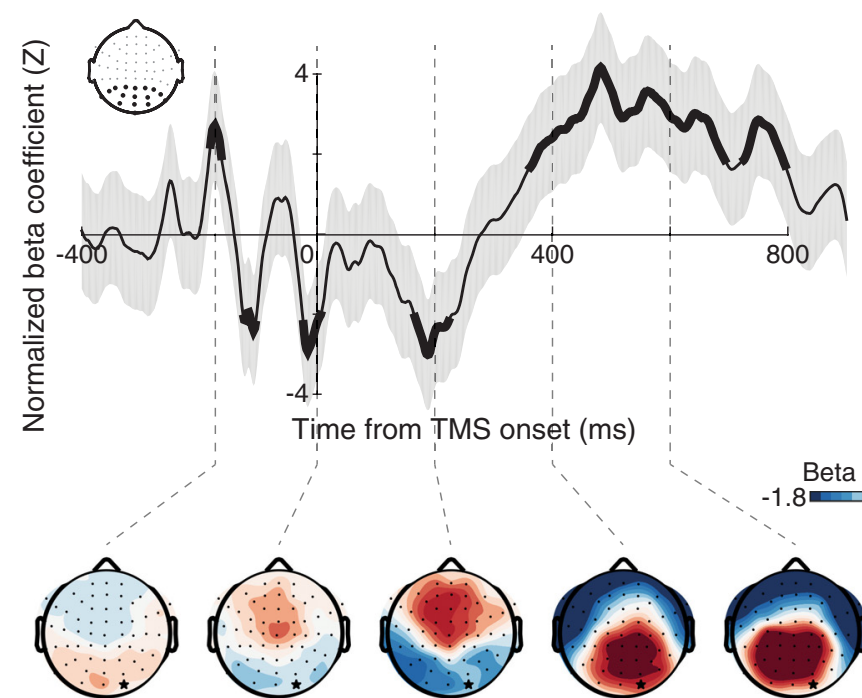

- $175 \mathrm{~ms}$

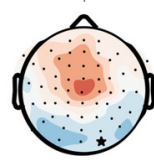

$0 \mathrm{~ms}$
Occipital TMS

Occipital TMS 
ment (TFCE) to address multiple comparisons across time and frequency points. To estimate group-level null hypothesis distributions, on each of 5000 permutations, $z$-scores from a random subset of subjects were multiplied by -1 and a $t$ test against zero was computed. This is equivalent to randomly swapping the order of the condition subtraction; for example, A-B versus B-A (Maris and Oostenveld, 2007). The $t$-statistic resulting from the true data mapping was then subject to TFCE as implemented in the LIMO EEG package (Pernet et al., 2011), which uses the algorithm developed by Smith and Nichols (2009). Each permutated $t$ statistic was also submitted to TFCE, forming a distribution of cluster extents expected under the null hypothesis. Only cluster extents in the real data exceeding an $\alpha$ rate of $0.05 \%$ were considered statistically significant. This procedure has been shown to control well the familywise error rate across multiple comparisons while taking into account the autocorrelation of electrophysiological data (Pernet et al., 2015). All tests were two-tailed.

\section{Results}

\section{Phosphene ratings}

The average rating of phosphene presence $( \pm \mathrm{SD}$ ) was $42.5 \pm 8.9$ (of 100) after occipital stimulation and $41.8 \pm 4.8$ after stimulation, confirming that our thresholding procedure was effective. As shown in Figure $1 C$, subjects made use of the full range of the scale, although with varying degrees of gradedness (i.e., some subjects used the end point values more frequently than others). When sorted into 11 bins (as in Fig. 1C), the shape of the groupaveraged histogram had four local maxima that were the same for occipital and parietal TMS. These peaks were at ratings of $4.5,22.7,68.18$, and 95.5, consistent with previous work that identified 4 "categories" of perceptual experience underlying the use of continuous perceptual scales (Ramsøy and Overgaard, 2004; Overgaard et al., 2006). As expected, ratings on no-TMS trials were near zero $(1.9 \pm 3)$, indicating basic task compliance and ensuring that subjects understood the directionality of the scale. These results suggest that additional information can be gained by allowing subjective perceptual responses to take a nonbinary form.

Time-domain correlates of phosphene perception

ERP's contrasting high and low perceptual ratings are presented in Figure $2 A$. High phosphene presence trials were associated with larger TMS-evoked VAN amplitudes after both occipital $\left(t_{(1,9)}=-4.39, p=0.002\right)$ and parietal $\left(t_{(1,9)}=-3.79, p=\right.$ $0.004)$ TMS. This effect was similar across stimulation conditions, but had a more temporal-occipital scalp distribution in the occipital TMS condition and more central occipital-parietal distribution in the parietal TMS condition. High ratings were also associated with an enhanced LP potential over posterior electrodes for occipital $\left(t_{(1,9)}=4.68, p=0.001\right)$ and parietal $\left(t_{(1,9)}=5.49, p<0.001\right)$ TMS. These results were also borne out of the single-trial regression analysis (Fig. $2 B$ ). In addition to significant negative correlations in the VAN time range (180$220 \mathrm{~ms}$ ) and positive correlations in the LP time range (300-
800), the single-trial analyses revealed a robust prestimulus correlation during the occipital TMS condition. This prestimulus correlation had a reversing polarity over time, with a period of $\sim 100 \mathrm{~ms}$, suggesting that the prestimulus alpha-band phase influenced phosphene perception. The scalp distributions of these significant regression parameters highly resemble those attained from the ERP analysis, with the early (200 ms) effect being maximal over occipital-temporal electrodes after occipital TMS and maximal over central occipital-parietal electrodes after parietal TMS and the late effect being parietal-maximal in both stimulation conditions.

\section{Time-frequency power correlates of phosphene perception}

The relationship between single-trial phosphene perception and oscillatory power across time and frequency space is shown in Figure 3. The analysis of occipital TMS data revealed a negative relationship between prestimulus low-frequency power $(\sim 5-13$ $\mathrm{Hz}$ ) and perception that had a posterior scalp distribution. TMSevoked low-frequency power $(\sim 3-6 \mathrm{~Hz})$ between $\sim 140$ and 400 ms over lateral occipital electrodes was positively correlated with phosphene perception, whereas later $(\sim 250-900 \mathrm{~ms})$ posterior alpha/beta power was robustly negatively correlated with perceptual ratings. Regarding parietal TMS, no clear effect of prestimulus low-frequency power was observed; rather, pre- 
A

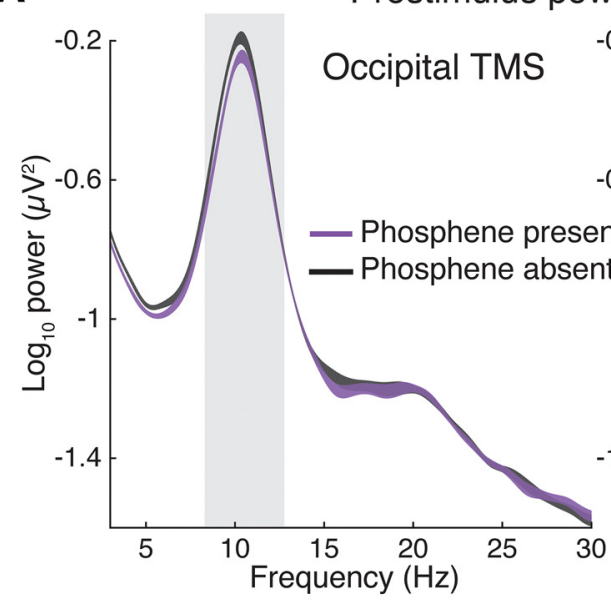

Prestimulus power spectrum

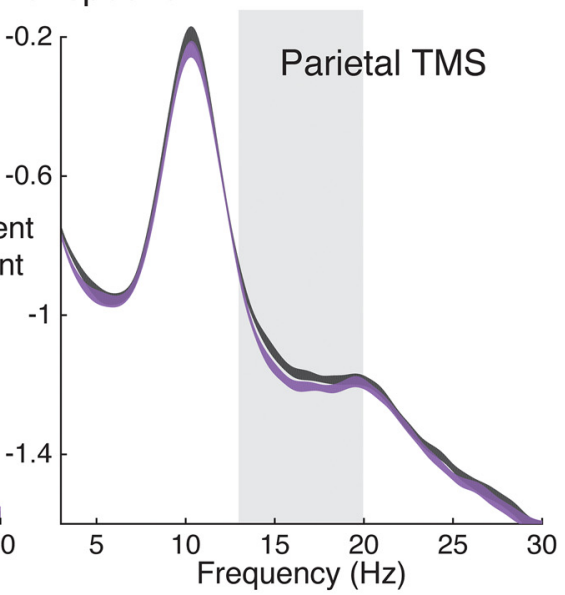

C

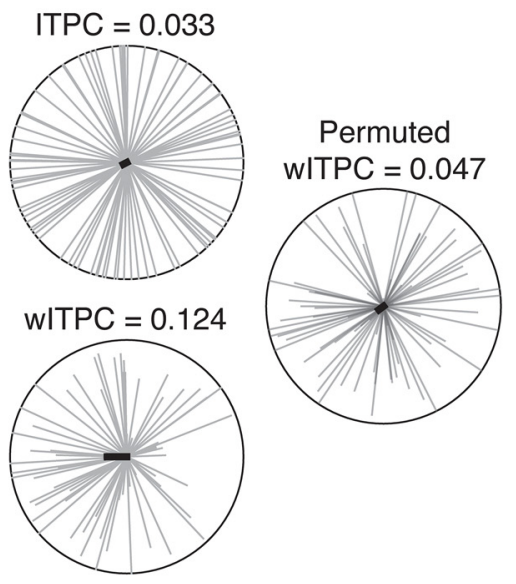

\section{B}

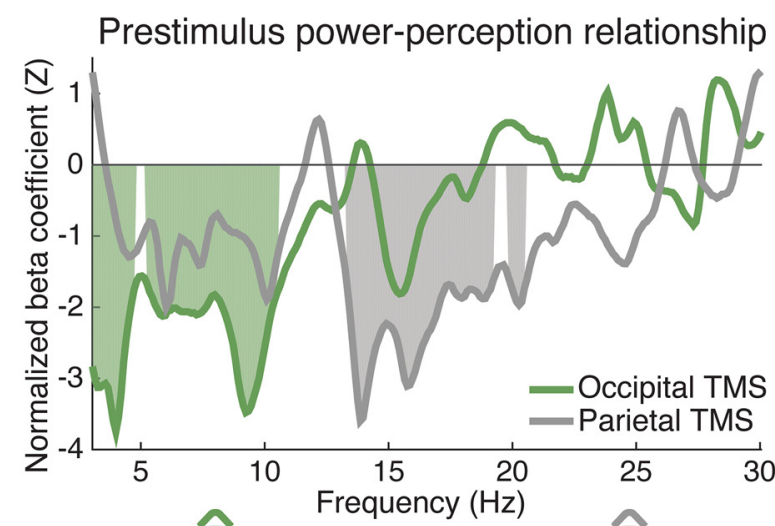

D
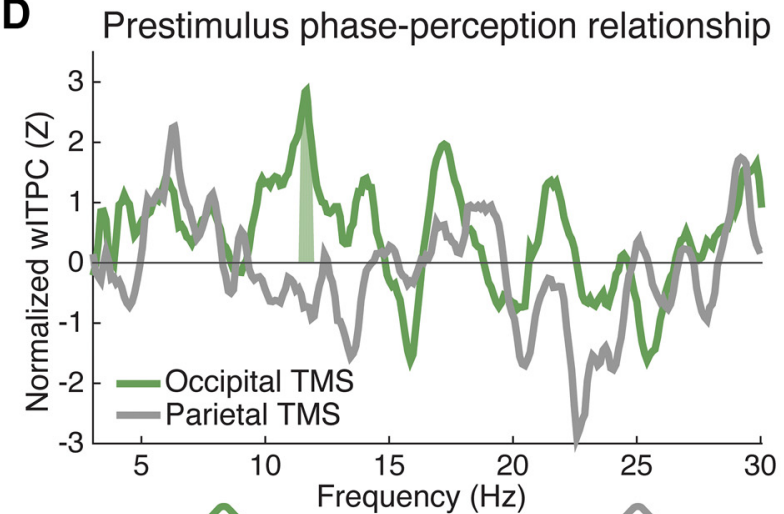

\section{$3-11 \mathrm{~Hz}$}
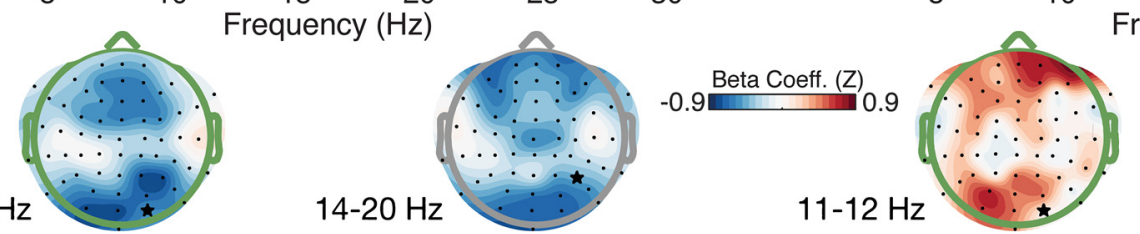

$14-20 \mathrm{~Hz}$

$11-12 \mathrm{~Hz}$

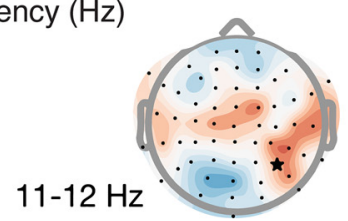

Figure 4. Relationship of prestimulus power and phase with phosphene perception. $A$, Prestimulus power spectra showing modulation of alpha-band power before occipital TMS and beta-band power before parietal TMS as a function of phosphene perception. Gray windows highlight frequency bands of interest for statistical analysis. Bands are \pm 1 within-subject SEM. $\boldsymbol{B}$, This same pattern was borne out of a single-trial regression analysis on prestimulus power, demonstrating negative correlations between low-frequency power and occpital TMS phosphene perception (green line) and between beta-band power and parietal TMS phosphene perception (gray line). The topographies of both effects are maximal over posterior and frontal sensors. $C$, Example computation of wITPC to relate single-trial phase to perception. Top left, Single-trial prestimulus phase vectors are shown as gray lines and are not clustered across trials due to the randomization of the intertrial interval, leading to a low resultant vector length (i.e., low ITPC). Bottom left, Length of each trial's phase vector is then weighted by that trial's phosphene rating (here normalized between 0 and 1 ) and a weighted ITPC is computed, reflecting the degree of phase-perception correlation. Right, This quantity gets normalized with respect to a null distribution attained by shuffling phosphene ratings across trials. D, Computing normalized wITPC across frequencies revealed that the prestimulus phase in the alpha band $(\sim 11.6 \mathrm{~Hz})$ was predictive of phosphene perception during occipital TMS. No phase-perception relationship was found for parietal TMS. Shaded portions under each line denote significant cluster-corrected effects.

stimulus high-alpha/low-beta power $(10-24 \mathrm{~Hz})$ was negatively related to phosphene perception. The topography of this effect was more widespread, with both a posterior and a central-frontal distribution. The relationship between TMS-evoked power and phosphene perception after parietal TMS closely resembled that of occipital stimulation: early low-frequency power was positively predictive of perceptual ratings, followed by a broadband alpha/beta component that was negatively related to phosphene perception.

Prestimulus oscillatory power predicts phosphene perception Figure $4 A$ shows a complementary analysis of power focused just on the prestimulus interval to avoid any contamination from poststimulus, TMS-induced responses (Zoefel and Heil, 2013). Power spectra of prestimulus data from trials with high and low phosphene ratings show a clear alpha-band peak with a power that was higher on low perceptual rating occipital TMS trials $\left(t_{(1,9)}=-3.82, p=0.004\right)$. In contrast, during parietal TMS, prestimulus beta power was significantly lower on trials with high phosphene presence ratings $\left(t_{(1,9)}=-2.92, p=0.017\right)$. A repeated-measures ANOVA predicting power from phosphene ratings (low, high), TMS site (occipital, parietal), and frequency (alpha, beta) revealed a significant 2-way interaction $\left(F_{(1,9)}=\right.$ $21.15, p=0.001)$, indicating that the effect of power on phosphene perception depended on stimulation site and frequency. The results of the single-trial regression analysis (Fig. $4 B$ ) revealed a clear distinction between the prestimulus predictors of phosphenes after occipital and parietal TMS, with broad-band low-frequency power $(3-13 \mathrm{~Hz})$ negatively correlating with occipital TMS phosphene perception and higher-frequency betaband $(12-22 \mathrm{~Hz})$ power negatively correlating with parietal TMS 
phosphene perception. The topographies of the regression coefficients closely resembled those obtained from the timefrequency analysis described above, with both having maximal effects over posterior as well as frontal sensors. The interaction between stimulation site and frequency band was assessed with a paired $t$ test on the double subtraction of normalized beta coefficients during occipital and parietal TMS between the alpha- and beta-bands. Consistent with the 2-way interaction reported above, this revealed that the relationship between prestimulus power and phosphene perception depended on stimulation site and frequency $\left(t_{(1,9)}=4.74, p=0.001\right)$.

Prestimulus alpha phase predicts phosphenes after occipital TMS

Figure $4 C$ depicts an example of wITPC computation (Cohen, 2014) using a single subject's prestimulus alpha phase during occipital TMS to predict phosphene perception (see "Time-frequency analysis" section for more details). The results of this procedure applied across frequencies revealed a significant phase-perception relationship in the alpha band (peak at $11.6 \mathrm{~Hz}$ ) during occipital TMS, which was marginally larger than that observed during parietal TMS $\left(t_{(1,9)}=2.24\right.$, $p=0.052)$. This effect was maximal over both occipital and frontal electrodes. No significant phase-perception effects survived correction for multiple comparisons during parietal TMS. The effect of prestimulus alpha phase on phosphene reports was further demonstrated by binning trials into 7 bins according to prestimulus phase at $11.6 \mathrm{~Hz}$ (normalized to percentage change relative to the mean across all bins). As shown in Figure 5, this revealed a clear modulation of perceptual rating according to prestimulus phase during occipital TMS $\left(F_{(6,54)}=3.23, p=\right.$ $0.008)$, but not parietal TMS $\left(F_{(6,54)}=1.88, p=0.102\right)$, as determined from a one-way ANOVA predicting phosphene reports from phase bin. A further 2-by-7 ANOVA including an interaction term between phase bin and TMS site revealed a significant interaction $\left(F_{(6,54)}=6.53, p<0.001\right)$, indicating that the prestimulus alpha phase effect depended on stimulation site. Although this interaction could be driven either by a true lack of a phase relationship during parietal TMS or by a comparable phase relationship just centered on a different preferred phase, we think the latter is unlikely given the lack of significant alpha phase modulation during parietal TMS in addition to the results of the between-site difference in the wITPCz analysis, which is insensitive to preferred phase.

\section{Discussion}

We applied TMS to occipital and PPC at phosphene thresholds while recording EEG. We replicated two previous findings demonstrating a negative relationship between prestimulus alpha power and phosphene reports (Romei et al., 2008a) and a dependence of phosphene perception on prestimulus alpha phase (Dugué et al., 2011). Notably, when phosphenes were induced through stimulation of PPC, we found that prestimulus beta-band power $(13-20 \mathrm{~Hz})$ was negatively correlated with phosphene perception and no phase dependence was observed. TMS-evoked responses differentiated levels of phosphene perception $\sim 180 \mathrm{~ms}$ after TMS onset at both stimulation sites
Phase at $11.6 \mathrm{~Hz}$
Occipital TMS

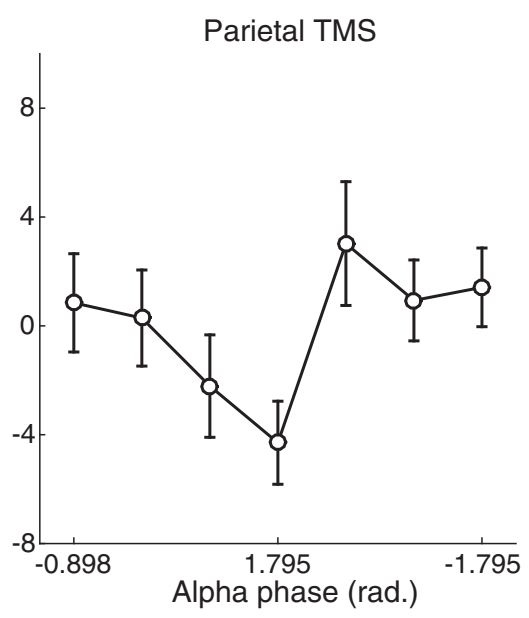

.795

$-1.795$ (1)
Figure 5. Prestimulus alpha phase predicts perception of occipital, but not parietal, TMS phosphenes. To futher inspect the phase at $11.6 \mathrm{~Hz}$. This revealed a significant modulation of occipital TMS phosphene ratings of $\sim 11 \%$ (peak to trough), but no
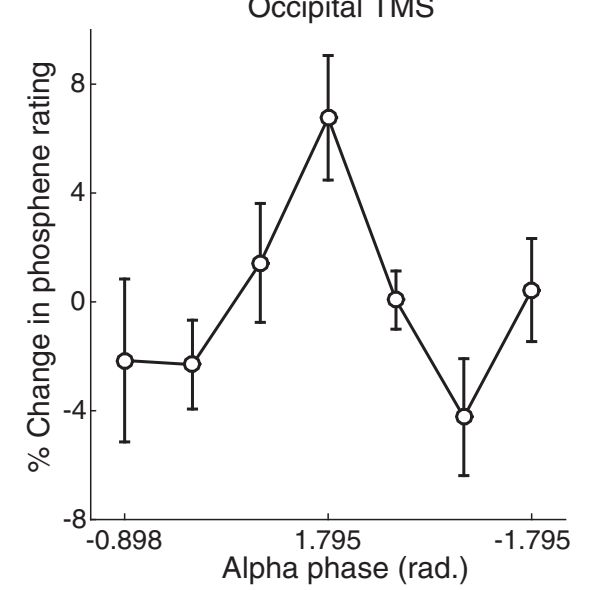

and was associated with an early negativity and a later central parietal positivity. Time-frequency responses indicated that phosphene perception was associated with increased power in the theta range, followed by a sustained decrease of power in the alpha/beta range for both stimulation sites.

Rethinking alpha power as a general index of cortical excitability Prevailing theory regards alpha-band oscillations as reflecting mechanisms of inhibition that can be routed across brain areas so as to suppress activity in task-irrelevant neural populations (Klimesch et al., 2007; Romei et al., 2008b; Jensen and Mazaheri, 2010; Foxe and Snyder, 2011; Haegens et al., 2011b; de Pesters et al., 2016). Given the link between alpha dynamics and excitability in occipital (Romei et al., 2008a; Dugué et al., 2011) and motor cortex (Zarkowski et al., 2006; Sauseng et al., 2009) and observations of attentional modulation of alpha power in somatosensory (Haegens et al., 2011a), auditory (Banerjee et al., 2011), and retinotopic regions (Worden et al., 2000; Sauseng et al., 2005; Samaha et al., 2016b), it is thought that alpha oscillations reflect a general mechanism of functional inhibition across cortex (Payne and Sekuler, 2014). Although we replicate prior findings linking phosphene perception to prestimulus alpha dynamics during occipital TMS, the finding that prestimulus beta power was predictive of PPC TMS phosphenes is in direct contrast to the notion that alpha reflects excitability across all of cortex.

Several lines of evidence also suggest that the idea of alpha as reflecting inhibition across cortex is overly simplistic. For instance, visual-evoked multiunit and gamma-band activity in macaque inferotemporal cortex correlate positively with prestimulus alpha power in the local field potential, which was also found to increase when attention was paid to visual, as opposed to auditory, input (Mo et al., 2011). Similarly, in humans, predictions about an upcoming stimulus have been shown to increase alpha power yet result in larger evoked responses, with the two processes being positively correlated (Mayer et al., 2016; Samaha et al., 2016a). A possible explanation for our finding that prestimulus beta power, rather than alpha, predicted PPC TMS phosphenes is suggested by recent work reporting that the dominant frequency evoked by TMS to occipital cortex is $\sim 10 \mathrm{~Hz}$, whereas the dominant frequency of the PPC TMS-evoked response is $\sim 20 \mathrm{~Hz}$ (Rosanova et al., 2009; Ferrarelli et al., 2012). Prestimulus beta dynamics have been shown recently to predict the global mean field amplitude of the evoked response after parietal 
TMS (Kundu et al., 2014). Therefore, beta-band oscillations may reflect the dominant frequency of PPC and alpha may reflect the dominant frequency of occipital cortex. We extend this work by showing that alpha and beta reflect directly the excitability of occipital cortex and PPC, respectively.

\section{Neural correlates of consciousness and phosphene perception}

Phosphene perception for both stimulation sites was associated with enhanced VAN and LP components in the time domain (Fig. 2). These two components have been studied intensively using visual stimuli (for reviews, see: Koivisto and Revonsuo, 2010; Railo et al., 2011; Rutiku et al., 2016), but disagreement about which reflects the neural correlate of consciousness persists (Aru et al., 2012; Railo et al., 2015). The LP potential (sometimes called the P3) has been argued to reflect the neural correlate of consciousness by proponents of the neuronal global workspace theory (Salti et al., 2015). In this context, the LP is thought to reflect widespread activation of a network of prefrontal and parietal regions that comprise the global workspace and underlie consciousness (Dehaene and Changeux, 2011). In contrast, the VAN is typically distributed over posterior sensors, though it may have a frontal component as well (Railo et al., 2015), and is observed earlier, typically between 180 and $260 \mathrm{~ms}$ (Koivisto et al., 2008; Railo et al., 2015), although it is often delayed in response to low-contrast stimuli (Railo et al., 2011; Tagliabue et al., 2016). The VAN is sometimes interpreted as reflecting recurrent processes in visual cortex hypothesized to underlie awareness (Fahrenfort et al., 2007; Koivisto et al., 2008). Support for the VAN as a correlate of consciousness has come from research suggesting that attention and/or introspection may account for the LP, but not VAN, modulation with awareness (Pitts et al., 2014b, 2014a; Shafto and Pitts, 2015) and from work demonstrating superior decodability of visibility from VAN versus LP time windows (Andersen et al., 2016). Activity in the LP time window, however, has been shown to contain stimulus specific information that covaries with subjective awareness (Salti et al., 2015).

In the present study, both components were robustly correlated with phosphene perception in both stimulation conditions. Although we cannot unambiguously identify the phosphenerelated activity reported here as the VAN and LP components that have been identified in studies using visual stimuli, we do see marked similarities in timing, scalp topography, waveform polarity, and the direction of perception-related effects. Because the waveforms in our study reflect not only proximal (i.e., 40-100 ms) brain activity induced solely by TMS (i.e., "TMS-evoked potentials"; TEP), but also perceptual- and cognitive-related activity underlying the perceptual experience of phosphenes and the perceptual decision making processes involved in performing the task, we would expect perception-related effects beyond the initial TEP, which is consistent with the timing of visual awareness (Dehaene and Changeux, 2011; Railo et al., 2011). Although the timing of the effects that we observed is consistent with previous ERP correlates of phosphene perception (Taylor et al., 2010; Dugué et al., 2011; Bagattini et al., 2015), we did not replicate the earliest $(\sim 100 \mathrm{~ms})$ effects observed by Bagattini et al. (2015).

Interestingly, the topography of LP modulation was maximal over central-parietal sensors for both stimulation conditions, whereas the VAN modulation was slightly more pronounced over lateral temporal-occipital sensors after occipital TMS and had a central occipital-parietal distribution after PPC TMS, a pattern closely resembling that observed in a recent ERP experiment with occipital and parietal TMS phosphenes (Bagattini et al., 2015). This implies that the early activity associated with phosphene perception may be generated in nearby but distinguishable cortical regions depending on the initial site of stimulation. This is intriguing because it implies that there may be several, rather than a single, neural correlates of phosphene perception. It further suggests that the VAN "component" is not necessarily a unitary phenomenon reflecting the activation of a single neural region related to visual awareness. In fact, it has been demonstrated recently that hemianopic patients with complete loss of primary visual cortex in one hemisphere are still capable of perceiving phosphenes in their blind field when ipsilesional PPC is stimulated (Mazzi et al., 2014; Bagattini et al., 2015). This strongly undermines the presumed visual-cortical origin of PPC TMS phosphenes and supports the notion that the VAN associated with PPC TMS need not be visual-cortical in origin and need not reflect recurrent processing involving visual cortex, both of which are often assumed of the VAN component (Railo et al., 2011, 2015; Andersen et al., 2016).

We also found that phosphene perception in both stimulation conditions was positively related to power in the theta range beginning $\sim 140 \mathrm{~ms}$ and negatively related to alpha/beta power extending from $250 \mathrm{~ms}$ until the response screen (Fig. 3). Whereas this early positive theta correlation likely reflects the same phaselocked activity underlying the VAN modulation, which occurs during the same time frame, the later negative correlation with alpha/beta power reflects dynamics that are not phase locked with TMS onset and are thus not observed in the ERP, a signature of a truly oscillatory neural process (Cohen and Donner, 2013). Poststimulus alpha/beta desynchronization has long been linked to perceptual processing (Pfurtscheller et al., 1994; Sewards and Sewards, 1999; Babiloni et al., 2006) and is thought to reflect disinhibition of widespread cortical networks involved in perceptual inference and decision making (Klimesch et al., 2007; Donner and Siegel, 2011). Here, we show that this well known signature of perceptual processing extends to phosphene perception and is strikingly similar regardless of the cortical origin of stimulation.

\section{References}

Andersen LM, Pedersen MN, Sandberg K, Overgaard M (2016) Occipital MEG activity in the early time range $(<300 \mathrm{~ms})$ predicts graded changes in perceptual consciousness. Cereb Cortex 26:2677-2688. CrossRef Medline

Aru J, Bachmann T, Singer W, Melloni L (2012) Distilling the neural correlates of consciousness. Neurosci Biobehav Rev 36:737-746. CrossRef Medline

Babiloni C, Vecchio F, Bultrini A, Luca Romani G, Rossini PM (2006) Preand poststimulus alpha rhythms are related to conscious visual perception: a high-resolution EEG study. Cereb Cortex 16:1690-1700. Medline

Bagattini C, Mazzi C, Savazzi S (2015) Waves of awareness for occipital and parietal phosphenes perception. Neuropsychologia 70:114-125. CrossRef Medline

Banerjee S, Snyder AC, Molholm S, Foxe JJ (2011) Oscillatory alpha-band mechanisms and the deployment of spatial attention to anticipated auditory and visual target locations: supramodal or sensory-specific control mechanisms? J Neurosci 31:9923-9932. CrossRef Medline

Busch NA, Dubois J, VanRullen R (2009) The phase of ongoing EEG oscillations predicts visual perception. J Neurosci 29:7869-7876. CrossRef Medline

Cohen MX (2014) Analyzing neural time series data: theory and practice. Cambridge, MA: MIT.

Cohen MX, Cavanagh JF (2011) Single-trial regression elucidates the role of prefrontal theta oscillations in response conflict. Front Psychol 2:30. CrossRef Medline

Cohen MX, Donner TH (2013) Midfrontal conflict-related theta-band power reflects neural oscillations that predict behavior. J Neurophysiol 110:2752-2763. CrossRef Medline

Cohen MX, Voytek B (2013) Linking nonlinear neural dynamics to single- 
trial human behavior. In: Multiscale analysis and nonlinear dynamics (Pesenson M, Meyer Z, ed), pp. 217-232. New York: Wiley.

Dehaene S, Changeux JP (2011) Experimental and theoretical approaches to conscious processing. Neuron 70:200-227. CrossRef Medline

Delorme A, Makeig S (2004) EEGLAB: an open source toolbox for analysis of single-trial EEG dynamics including independent component analysis. J Neurosci Methods 134:9-21. CrossRef Medline

de Pesters A, Coon WG, Brunner P, Gunduz A, Ritaccio AL, Brunet NM, de Weerd P, Roberts MJ, Oostenveld R, Fries P, Schalk G (2016) Alpha power indexes task-related networks on large and small scales: a multimodal ECoG study in humans and a non-human primate. Neuroimage 134:122-131. CrossRef Medline

Donner TH, Siegel M (2011) A framework for local cortical oscillation patterns. Trends Cogn Sci 15:191-199. CrossRef Medline

Dugué L, Marque P, VanRullen R (2011) The phase of ongoing oscillations mediates the causal relation between brain excitation and visual perception. J Neurosci 31:11889-11893. CrossRef Medline

Fahrenfort JJ, Scholte HS, Lamme VA (2007) Masking disrupts reentrant processing in human visual cortex. J Cogn Neurosci 19:1488-1497. CrossRef Medline

Ferrarelli F, Sarasso S, Guller Y, Riedner BA, Peterson MJ, Bellesi M, Massimini M, Postle BR, Tononi G (2012) Reduced natural oscillatory frequency of frontal thalamo-cortical circuits in schizophrenia. Arch Gen Psychiatry 69:766-774. Medline

Foxe JJ, Snyder AC (2011) The role of alpha-band brain oscillations as a sensory suppression mechanism during selective attention. Front Psychol 2:154. CrossRef Medline

Fried PJ, Elkin-Frankston S, Rushmore RJ, Hilgetag CC, Valero-Cabre A (2011) Characterization of visual percepts evoked by noninvasive stimulation of the human posterior parietal cortex. PLoS One 6:e27204. CrossRef Medline

Garcia D (2010) Robust smoothing of gridded data in one and higher dimensions with missing values. Comput Stat Data Anal 54:1167-1178. CrossRef Medline

Haegens S, Händel BF, Jensen O (2011a) Top-down controlled alpha band activity in somatosensory areas determines behavioral performance in a discrimination task. J Neurosci 31:5197-5204. CrossRef Medline

Haegens S, Nácher V, Luna R, Romo R, Jensen O (2011b) $\alpha$-Oscillations in the monkey sensorimotor network influence discrimination performance by rhythmical inhibition of neuronal spiking. Proc Natl Acad Sci U S A 108:19377-19382. CrossRef Medline

Jensen O, Mazaheri A (2010) Shaping functional architecture by oscillatory alpha activity: gating by inhibition. Front Hum Neurosci 4:186. CrossRef Medline

Kammer T, Puls K, Erb M, Grodd W (2005) Transcranial magnetic stimulation in the visual system. II. Characterization of induced phosphenes and scotomas. Exp Brain Res 160:129-140. CrossRef Medline

Klimesch W, Sauseng P, Hanslmayr S (2007) EEG alpha oscillations: the inhibition-timing hypothesis. Brain Res Rev 53:63-88. CrossRef Medline

Koivisto M, Revonsuo A (2010) Event-related brain potential correlates of visual awareness. Neurosci Biobehav Rev 34:922-934. CrossRef Medline

Koivisto M, Lähteenmäki M, Sørensen TA, Vangkilde S, Overgaard M, Revonsuo A (2008) The earliest electrophysiological correlate of visual awareness? Brain Cogn 66:91-103. CrossRef Medline

Kundu B, Johnson JS, Postle BR (2014) Prestimulation phase predicts the TMS-evoked response. J Neurophysiol 112:1885-1893. CrossRef Medline

Maris E, Oostenveld R (2007) Nonparametric statistical testing of EEG- and MEG-data. J Neurosci Methods 164:177-190. CrossRef Medline

Marzi CA, Mancini F, Savazzi S (2009) Interhemispheric transfer of phosphenes generated by occipital versus parietal transcranial magnetic stimulation. Exp Brain Res 192:431-441. CrossRef Medline

Massimini M, Ferrarelli F, Huber R, Esser SK, Singh H, Tononi G (2005) Breakdown of cortical effective connectivity during sleep. Science 309: 2228-2232. CrossRef Medline

Mathewson KE, Gratton G, Fabiani M, Beck DM, Ro T (2009) To see or not to see: pre-stimulus alpha phase predicts visual awareness. J Neurosci 29:2725-2732. CrossRef Medline

Mathewson KE, Lleras A, Beck DM, Fabiani M, Ro T, Gratton G (2011) Pulsed out of awareness: EEG alpha oscillations represent a pulsedinhibition of ongoing cortical processing. Front Psychol 2:99. CrossRef Medline
Mayer A, Schwiedrzik CM, Wibral M, Singer W, Melloni L (2016) Expecting to see a letter: alpha oscillations as carriers of top-down sensory predictions. Cereb Cortex 26:3146-3160. CrossRef Medline

Mazzi C, Mancini F, Savazzi S (2014) Can IPS reach visual awareness without V1? Evidence from TMS in healthy subjects and hemianopic patients. Neuropsychologia 64:134-144. CrossRef Medline

Merton PA, Hill DK, Morton HB, Marsden CD (1982) Scope of a technique for electrical stimulation of human brain, spinal cord, and muscle. Lancet 2:597-600. Medline

Mo J, Schroeder CE, Ding M (2011) Attentional modulation of alpha oscillations in macaque inferotemporal cortex. J Neurosci 31:878-882. CrossRef Medline

Overgaard M, Rote J, Mouridsen K, Ramsøy TZ (2006) Is conscious perception gradual or dichotomous? A comparison of report methodologies during a visual task. Conscious Cogn 15:700-708. CrossRef Medline

Pascual-Leone A, Tormos JM, Keenan J, Tarazona F, Cañete C, Catalá MD (1998) Study and modulation of human cortical excitability with transcranial magnetic stimulation. J Clin Neurophysiol 15:333-343. CrossRef Medline

Payne L, Sekuler R (2014) The importance of ignoring alpha oscillations protect selectivity. Curr Dir Psychol Sci 23:171-177. CrossRef Medline

Pernet CR, Chauveau N, Gaspar C, Rousselet GA (2011) LIMO EEG: a toolbox for hierarchical linear modeling of electroencephalographic data. Comput Intell Neurosci 2011:831409. CrossRef Medline

Pernet CR, Latinus M, Nichols TE, Rousselet GA (2015) Cluster-based computational methods for mass univariate analyses of event-related brain potentials/fields: a simulation study. J Neurosci Methods 250:8593. CrossRef Medline

Pfurtscheller G, Neuper C, Mohl W (1994) Event-related desynchronization (ERD) during visual processing. Int J Psychophysiol 16:147-153. CrossRef Medline

Pitts MA, Metzler S, Hillyard SA (2014a) Isolating neural correlates of conscious perception from neural correlates of reporting one's perception. Front Psychol 5:1078. CrossRef Medline

Pitts MA, Padwal J, Fennelly D, Martínez A, Hillyard SA (2014b) Gamma band activity and the P3 reflect post-perceptual processes, not visual awareness. Neuroimage 101:337-350. CrossRef Medline

Railo H, Koivisto M, Revonsuo A (2011) Tracking the processes behind conscious perception: a review of event-related potential correlates of visual consciousness. Conscious Cogn 20:972-983. CrossRef Medline

Railo H, Revonsuo A, Koivisto M (2015) Behavioral and electrophysiological evidence for fast emergence of visual consciousness. Neurosci Conscious Available from: https://www.researchgate.net/publication/280572811_Behavioral_and_ electrophysiological_evidence_for_fast_emergence_of_visual_consciousness. Accessed August 19, 2015.

Ramsøy TZ, Overgaard M (2004) Introspection and subliminal perception. Phenomenol Cogn Sci 3:1-23. CrossRef

Romei V, Brodbeck V, Michel C, Amedi A, Pascual-Leone A, Thut G (2008a) Spontaneous fluctuations in posterior $\alpha$-band EEG activity reflect variability in excitability of human visual areas. Cereb Cortex 18:2010-2018. CrossRef Medline

Romei V, Rihs T, Brodbeck V, Thut G (2008b) Resting electroencephalogram alpha-power over posterior sites indexes baseline visual cortex excitability. Neuroreport 19:203-208. CrossRef Medline

Rosanova M, Casali A, Bellina V, Resta F, Mariotti M, Massimini M (2009) Natural frequencies of human corticothalamic circuits. J Neurosci 29: 7679-7685. CrossRef Medline

Rutiku R, Aru J, Bachmann T (2016) General markers of conscious visual perception and their timing. Front Hum Neurosci 10:23. CrossRef Medline

Salti M, Monto S, Charles L, King J-R, Parkkonen L, Dehaene S (2015) Distinct cortical codes and temporal dynamics for conscious and unconscious percepts. eLife 4. CrossRef Medline

Samaha J, Bauer P, Cimaroli S, Postle BR (2015) Top-down control of the phase of alpha-band oscillations as a mechanism for temporal prediction. Proc Natl Acad Sci U S A 112:8439-8444. CrossRef Medline

Samaha J, Boutonnet B, Lupyan G (2016a) How prior knowledge prepares perception: prestimulus oscillations carry perceptual expectations and influence early visual responses. Available from: http:// biorxiv.org/content/biorxiv/early/2016/09/21/076687.full.pdf. Accessed October 17, 2016.

Samaha J, Sprague TC, Postle BR (2016b) Decoding and reconstructing the 
focus of spatial attention from the topography of alpha-band oscillations. J Cogn Neurosci 28:1090-1097. CrossRef Medline

Sauseng P, Klimesch W, Stadler W, Schabus M, Doppelmayr M, Hanslmayr S, Gruber WR, Birbaumer N (2005) A shift of visual spatial attention is selectively associated with human EEG alpha activity. Eur J Neurosci 22:2917-2926. CrossRef Medline

Sauseng P, Klimesch W, Gerloff C, Hummel FC (2009) Spontaneous locally restricted EEG alpha activity determines cortical excitability in the motor cortex. Neuropsychologia 47:284-288. CrossRef Medline

Sewards TV, Sewards MA (1999) Alpha-band oscillations in visual cortex: part of the neural correlate of visual awareness? Int J Psychophysiol 32: 35-45. CrossRef Medline

Shafto JP, Pitts MA (2015) Neural signatures of conscious face perception in an inattentional blindness paradigm. J Neurosci35:10940-10948. CrossRefMedline

Smith SM, Nichols TE (2009) Threshold-free cluster enhancement: addressing problems of smoothing, threshold dependence and localisation in cluster inference. Neuroimage 44:83-98. CrossRef Medline

Tagliabue CF, Mazzi C, Bagattini C, Savazzi S (2016) Early local activity in temporal areas reflects graded content of visual perception. Front Psychol 7:572. CrossRef Medline

Tapia E, Mazzi C, Savazzi S, Beck DM (2014) Phosphene-guided transcranial magnetic stimulation of occipital but not parietal cortex suppresses stimulus visibility. Exp Brain Res 232:1989-1997. CrossRef Medline

Taylor PC, Walsh V, Eimer M (2010) The neural signature of phosphene perception. Hum Brain Mapp 31:1408-1417. CrossRef Medline

Worden MS, Foxe JJ, Wang N, Simpson GV (2000) Anticipatory biasing of visuospatial attention indexed by retinotopically specific $\alpha$-band electroencephalography increases over occipital cortex. J Neurosci 20:RC63-RC63. Medline

Zarkowski P, Shin CJ, Dang T, Russo J, Avery D (2006) EEG and the variance of motor evoked potential amplitude. Clin EEG Neurosci 37:247251. CrossRef Medline

Zoefel B, Heil P (2013) Detection of near-threshold sounds is independent of EEG phase in common frequency bands. Front Psychol 4:262. CrossRef Medline 